\title{
Avaliação de linhagens de feijão-de-vagem para as regiões Norte e Noroeste Fluminense ${ }^{1}$
}

\author{
Evaluation of Promising of snap bean to the North and Northwest Fluminense
}

\author{
Francisco Maurício Alves Francelino ${ }^{2 *}$, Geraldo de Amaral Gravina², Carmen Maria Coimbra Manhães ${ }^{3}$, \\ Poliane Marcele Ribeiro Cardoso ${ }^{4}$ e Lanusse Cordeiro de Araújo 5
}

\begin{abstract}
Resumo - O feijão-de-vagem é uma hortaliça rica em fibras, proteínas e vitaminas. Dentro do programa de melhoramento do feijão-de-vagem da Universidade Estadual do Norte Fluminense Darcy Ribeiro (UENF), foram realizadas seleções nas populações $\mathrm{F}_{2}$, em campo; avançando até $\mathrm{F}_{5}$ pelo método $\mathrm{SSD}$, em casa de vegetação; selecionando 30 linhas promissoras em $\mathrm{F}_{6}$. Continuando o programa, a geração $\mathrm{F}_{7}$ foi cultivada e avaliada, em campo, em Campos dos Goytacazes e em Bom Jesus do Itabapoana. As características avaliadas foram: altura de inserção da primeira vagem (APV); altura da planta (AP); o número médio de vagens por planta (NMV); comprimento médio das vagens (CMV); peso médio de grãos por vagem (PMGV); teor de fibras nas vagens (FIB); produtividade de vagens por hectare (ProdVagens) e a produtividade de grãos por hectare (ProdGrãos). Não houve interação genótipo x ambiente (local) para a característica teor de fibra nas vagens, indicando ser esta bastante estável aos ambientes estudados. O teste de Scott-Knot formou três grupos quanto ao teor de fibras nas vagens frescas. Houve efeito significativo de genótipos para todas as características avaliadas, exceto para o NMVP. Os acessos UENF 7-20-1, UENF 7-5-1, UENF 14-22-3, UENF 15-8-4, UENF 1445, Top seed blue line, Feltrin, UENF 14-16-3, UENF 7-10-1, UENF 14-6-3 e UENF 15-23-4 foram respectivamente os mais produtivos, com rendimentos de 20.052 a $15.873 \mathrm{Mg} \mathrm{ha}^{-1}$ de vagens e na produção de grãos (2.693 a $2.014 \mathrm{Mg} \mathrm{ha}^{-1}$ ). A característica mais correlacionada com os rendimentos de vagens e de grãos foi o NMVP seguido por CMV.
\end{abstract}

Palavras-chave - Feijão-de-Vagem. Caracteres agronômicos. Melhoramento genético.

\begin{abstract}
The snap bean is a vegetable rich in fibers, proteins and vitamins. Within of the breeding program of snap bean of Universidade Estadual do Norte Fluminense Darcy Ribeiro (UENF), selections were performed in F2 populations in the field, advancing to F5 by SSD method, in a greenhouse, selecting 30 promising lines in F6. Continuing the program, the F7 generation was cultivated and evaluated in the field in Campos dos Goytacazes and in Bom Jesus do Itabapoana. The characteristics evaluated were height of first pod insertion (APV), height of plants (AP), average number of pods per plant (NMV); average length of pods (CMV), average weight of grains per pod (PMGV); fiber content in pod (FIB), pod productivity per hectare (ProdVagens) and grains productivity per hectare (ProdGrãos). There has no interaction genotype x environment (local) for the characteristic fiber content in pod, indicating that this is very stable environments studied. The Scott-Knot test formed three groups as to fiber content in fresh pods. There was significative effect of genotypes for all characteristics considered, except for the NMVP. The accesses UENF 7-20-1, UENF 7-5-1, UENF 14-22-3, UENF 15-8-4, UENF 1445, Top seed blue line, Feltrin, UENF 14-16-3, UENF 7-10-1, UENF 14-6-3 and UENF 15-23-4 were respectively the most productive, with yields from 20,052 to $15,873 \mathrm{Mg} \mathrm{ha}^{-1}$ of pods and in grains yield (2,693 to 2,014 $\left.\mathrm{Mg} \mathrm{ha}^{-1}\right)$. The characteristic most correlated with the yield of pods and grain was NMVP followed by CMV.
\end{abstract}

Key words - Snap bean. Agronomic characters. Breeding.

\footnotetext{
* Autor para correspondência

'Recebido para publicação em 11/03/2010; aprovado em 16/02/2011

Parte da Dissertação de mestrado apresentada pelo primeiro autor no Programa de Pós-Graduação em Produção Vegetal/UENF, RJ

${ }^{2}$ Laboratório de Engenharia Agrícola, Centro de Ciências e Tecnologias Agropecuárias-CCTA, Universidade Estadual do Norte Fluminens, Campos dos Goytacazes-RJ, Brasil, 28.013-602,francelinofma@yahoo.com.br, gravina@uenf.br

${ }^{3}$ Laboratório de Solos, Centro de Ciências e Tecnologias Agropecuárias-CCTA, Universidade Estadual do Norte Fluminense, Campos dos Goytacazes-RJ, Brasil, 28.013-602, carmenmanhaes@yahoo.com.br

4Programa de Pós-Graduação em Produção Vegetal, Laboratório de Fitotecnia, Universidade Federal de Viçosa, Viçosa-MG, Brasil, polianemarcele@yahoo.com.br

${ }^{5}$ Programa de Pós-Graduação em Produção Vegetal, Laboratório de Engenharia Agrícola, Centro de Ciências e Tecnologias Agropecuárias-CCTA, Universidade Estadual do Norte Fluminense, Campos dos Goytacazes-RJ, Brasil, 28.013-602, lanusse@iff.edu.br
} 


\section{Introdução}

A produção de hortaliças no estado do Rio de Janeiro tem sua maior expressão na Região Serrana. No Norte e Noroeste, a tradição de se cultivar cana-deaçúcar, torna o volume de produção de hortaliças pequeno (CEASA-RJ, 2006). Porém não menos importante.

Para as Regiões Norte e Noroeste Fluminense, a importância da produção de feijão-de-vagem, torna-se evidente por ser uma cultura com boa adaptação a climas quentes e amenos. Entretanto ainda se procura uma cultivar totalmente adaptada.

Devido à importância da cultura do feijãode-vagem (Phaseolus vulgaris L.) no contexto da agricultura fluminense, a busca por materiais genéticos com características desejáveis à produção é de elevada importância. A alta produtividade pode ser obtida pelo uso de técnicas de cultivo mais aprimoradas ou pela utilização de cultivares geneticamente superiores, que se entende ser o mais promissor. Sendo de grande importância a utilização de programas de melhoramento para descoberta destes cultivares. Em programas de melhoramento genético deve ser priorizada a identificação de linhagens de feijão de alto potencial de rendimento de grãos e, depois, realizar a seleção da linhagem pelo teor de fibra (LONDERO et al., 2006).

A produção de feijão-de-vagem (Phaseolus vulgaris L.) para o consumo humano é caracterizada em grande parte por cultivares com hábito de crescimento indeterminado (QUEIROGA et al., 2003). Por isso, nas maiores regiões produtoras do estado do Rio de Janeiro têm sido utilizadas cultivares com este hábito de crescimento (ABREU, 2001) como uma opção de rotação de culturas em áreas já tradicionais no cultivo de tomate de mesa. Porém, a tendência é que novas cultivares com melhor ideótipo, que apresentem o porte mais ereto e com maior tolerância ao acamamento sejam desenvolvidas e recomendadas, visando aumentar o rendimento da produção (Anuário Estatístico do Rio de Janeiro, 1998), objetivando também o máximo de retorno econômico.

Pesquisas visando o melhoramento do feijão-devagem são de elevada importância. Algumas estão sendo desenvolvidas no Brasil, refletindo em melhorias no manejo e na produtividade da cultura. Entretanto, no Brasil o melhoramento de caracteres agronômicos e de qualidade do grão têm sido praticado de certo modo, empiricamente (KUREK et al., 2001). Sendo, as empresas privadas de produção de sementes as principais fontes de produção e liberação de novos cultivares de feijão-de-vagem.

A cultura do feijão-de-vagem necessita de implementação de pesquisas, principalmente no sentido de incrementar suas características para se obter maior produtividade. A interação genótipo x ambiente também deve ser pesquisada. Segundo Vale et al. (2009), o componente desta interação pode mostrar que uma planta vigorosa e produtiva, em determinado ambiente, pode não repetir o mesmo desempenho quando cultivada em outro ambiente.

Para a característica teor de fibra das vagens também há carência de pesquisas. De acordo com Londero et al. (2008), a quantificação do teor de fibra das vagens em genótipos de feijão comum, assim como de feijão-de-vagem é necessária, uma vez que ainda são recentes as pesquisas e poucas informações são disponibilizadas na literatura.

O objetivo deste trabalho foi realizar seleções em feijão-de-vagem cultivados em duas localidades, para avaliação das linhagens, visando o lançamento de material melhorado para os produtores do Norte e Noroeste Fluminense.

\section{Material e métodos}

AUniversidadeEstadualdoNorteFluminenseDarcy Ribeiro (UENF) iniciou um programa de melhoramento com feijão-de-vagem de hábito indeterminado, com a finalidade de selecionar genótipos produtivos e de qualidade comercial para o Norte e Noroeste Fluminense. O programa teve início com a caracterização e estudo da diversidade genética de 25 acessos do Banco de Germoplasma da UENF, de hábito indeterminado. A partir de então foram realizados vários cruzamentos entre acessos divergentes e posteriores seleções dos genótipos com características desejáveis. Foram realizadas seleções em campo pelo método SSD ("single seed descent" descendente de uma única semente por planta), e em casa de vegetação. Selecionando então, 30 linhas promissoras da geração $\mathrm{F}_{6}$ para este estudo.

Este trabalho foi realizado em duas estações experimentais do convênio UENF/PESAGRO-RIO em Campos dos Goytacazes (RJ) e UENF/IFF - Instituto Federal Fluminense Campus Bom Jesus do Itabapoana (RJ). Os tratamentos utilizados foram as 30 linhagens selecionadas de feijão-de-vagem, de hábito de crescimento indeterminado, do Programa de melhoramento da Universidade Estadual do Norte Fluminense, em andamento e para fins de comparação dos genótipos, em cada bloco foram incluídas as testemunhas "Top Seed Blue Line", "Feltrin" e o Progenitor 19 (UENF 1445).

Os experimentos foram conduzidos no período de março a agosto de 2008. Foi utilizado o delineamento experimental de blocos ao acaso com duas repetições, sendo avaliadas plantas individuais dentro de cada 
repetição (bloco). A parcela experimental era composta por 12 plantas, no espaçamento de $1,0 \times 0,5 \mathrm{~m}$ e, as análises foram realizadas com base nas 10 plantas centrais da fileira, sendo as duas plantas das extremidades mantidas para a produção de sementes. Utilizou-se bordadura ao redor de cada unidade experimental.

A semeadura foi realizada em maio de 2008, colocando-se três sementes por cova, e cerca de 15 dias após a emergência, as plantas foram desbastadas mantendose uma planta por cova e tutoradas com bambu e arame. Durante a condução do experimento, foram efetuados todos os tratos culturais e fitossanitários recomendados para a cultura, assim como irrigação por aspersão. Realizaram-se colheitas de vagens para análises e avaliações durante o período de produção do experimento, que teve duração de aproximadamente 120 dias.

Foram avaliadas as seguintes características:

a) Altura média da inserção da primeira vagem (APV) expressa em cm, obtida pela medição da distância do colo até a inserção da primeira vagem;

b) Altura de plantas (ALT): medida da altura das plantas, correspondendo à distância do colo até o final da haste principal, na data da última colheita, expressa em $\mathrm{cm}$;

c) Número médio de vagens por planta (NMVP);

d) Número médio de grãos por vagem (NMGV), obtido pela contagem do número de sementes em uma amostra de dez vagens por planta;

e) Comprimento médio da vagem (CMV), expresso em $\mathrm{cm}$, obtido pela quantificação do comprimento longitudinal de uma amostra de dez vagens por planta;

f) Peso médio de vagens por planta (PMV), obtido pela razão entre o peso total de vagens e o número de plantas, expresso em g;

g) Teor de fibra na vagem (FIB): obtido a partir de $10 \mathrm{~g}$ de vagens in natura, trituradas por três minutos em liquidificador; rotação média; em seguida, as amostras foram colocadas em peneiras de 30 mesh, lavadas em água corrente e, posteriormente, lavadas com acetona $(100 \%)$ e secas em estufa a $105{ }^{\circ} \mathrm{C}$ por cerca de uma hora, procedendo-se em seguida a pesagem do material. Adaptado de Frank et al. (1961);

h) Produtividade média de vagens (Prod. Vagens) expresso em $\mathrm{kg} \mathrm{ha}^{-1}$ de vagens frescas;

i) Produtividade de grãos (Prod. Grãos) expresso em $\mathrm{kg} \mathrm{ha}^{-1}$ de grãos secos.

Para todas elas, exceto para o teor de fibra na vagem (item g), foram avaliadas 10 plantas individualmente, por linha, em cada bloco. Para o teor de fibra, foi constituída uma amostra composta de cinco vagens, sendo uma de cada planta, escolhida aleatoriamente por linha, em cada bloco.

As análises genético-estatísticas foram realizadas utilizando-se o programa GENES (CRUZ, 1997). Foi utilizado o critério de Scott-Knott, em nível de significância de 5\% de probabilidade, para comparar as médias entre os acessos.

Após as análises de variâncias individuais, realizou-se o agrupamento dos experimentos dos dois locais, para uma análise conjunta. Este agrupamento obedeceu ao critério onde a ordem de grandeza dos quadrados médios dos resíduos não ultrapassa a relação de $7: 1$.

A análise de variância conjunta foi realizada para avaliar a interação genótipo x ambiente, a qual é de grande importância no melhoramento, pois, no caso de sua existência, há possibilidades de o melhor genótipo em um ambiente não o ser em outro. Este fato influencia o ganho de seleção e dificulta a recomendação de cultivares com ampla adaptabilidade.

\section{Resultados e discussão}

Houve efeito significativo de genótipos para todas as características avaliadas no experimento, ou seja, os diferentes genótipos podem ser distinguidos pelas suas características (TAB. 1). Da mesma forma, Machado et al. (2008) estudando diferentes genótipos de feijão-caupi precoces e de alta produtividade de grãos encontraram diferença significativa quanto a característica produtividade de grãos entre os genótipos estudados, conseguindo diferi-los pela produtividade de seus grãos.

O NMVP, a ALT e a Prod. de Vagens apresentaram efeito significativo das linhagens utilizadas a $5 \%$ de probabilidade pelo teste F. A APV, o NMGV, o CMV, o PMV, e a Produtividade de grãos foram altamente significativas a $1 \%$ de probabilidade, indicando que existe variabilidade genética entre as linhagens de feijão-devagem avaliadas.

A característica CMV apresentou maior variabilidade entre os genótipos, formando cinco classes diferentes, de acordo com o teste de ScottKnott, seguida da característica ALT, que permitiu a formação de quatro classes distintas (TAB. 2).

As características PMV e NMGV permitiram a formação de três classes, e as características APV, Prod. Grãos e Prod Vagens formaram duas classes cada (TAB. 2). 
Tabela 1 - Quadrados médios da análise de variância para o efeito de genótipos para oito características avaliadas no experimento de competição de linhagens de feijão-de-vagem, Bom Jesus de Itabapoana, 2008

\begin{tabular}{lrcr}
\hline \multicolumn{1}{c}{ Caráter } & Média & Quadrado Médio & CV\% \\
\hline NMVP (no) & 50,98 & $188,6954^{*}$ & 17,73 \\
APV (cm) & 8,71 & $6,8005^{*}$ & 22,17 \\
ALT (m) & 2,41 & $0,1707^{* *}$ & 6,32 \\
PMV (g) & 2,92 & $0,3575^{* *}$ & 11,51 \\
CMV (cm) & 13,86 & $11,3729^{* *}$ & 7,67 \\
NMGV (no) & 7,33 & $1,0513^{* *}$ & 6,79 \\
Prod. Grãos $\left(\mathrm{kg} \mathrm{ha}^{-1}\right)$ & $1.898,85$ & $303165,6^{* *}$ & 18,77 \\
Prod. Vag. $\left(\mathrm{kg} \mathrm{ha}^{-1}\right)$ & $14.656,77$ & $11743970,0^{*}$ & 17,66 \\
\hline
\end{tabular}

*,**significativo a $5 \%$ e a $1 \%$ de significância, pelo teste $\mathrm{F}$, respectivamente

A característica APV tem maior importância na cultura do feijão comum para a colheita mecanizada, o que não é interessante para o feijão-de-vagem de hábito indeterminado por ser uma cultura que visa o emprego da mão-de-obra familiar. Entretanto, é de interesse dos melhoristas selecionar genótipos que possuam maior altura de inserção das primeiras vagens, pois vagens baixas, devido ao contato com o solo podem ser facilmente deterioradas. As linhagens UENF 7-6-1, UENF 7-10-1, UENF 7-5-1, UENF 15-23-4, UENF 7-14-1, UENF 7-3-1, UENF 15-6-4, UENF 15-25-4, UENF 15-7-4, UENF 79-1 e UENF 15-8-4 apresentaram as maiores médias para esta característica (TAB. 2).

Os genótipos UENF 7-20-1, UENF 7-12-1, Top Seed Blue Line, UENF 14-23-3, Feltrin, UENF 7-10-1, UENF 1422-3, UENF 14-45, UENF 7-9-1, UENF 15-6-4, UENF 15-26-4 e UENF 15-7-4 foram os que apresentaram maiores alturas de planta. Vale a pena ressaltar que os genótipos UENF 14-45, Feltrin e Top Seed Blue Line são testemunhas, sendo o genótipo UENF 14-45 um dos genitores e os cultivares Feltrin e Top Seed que são variedades comerciais utilizadas para efeito de comparação com as linhagens em teste. Desta forma, estas linhagens citadas acima possuem altura semelhante às comerciais. A linhagem UENF 9-1-2 foi a que apresentou menor altura de planta $(1,47 \mathrm{~m})$, constituindo isoladamente uma classe. Os demais genótipos ficaram distribuídos nas duas classes intermediárias (TAB. 2).

Os resultados obtidos neste trabalho, para altura de plantas, variaram de 1,47 a 2,49 $\mathrm{m}$, podendo ser considerados como altos quando comparados com os encontrados por ABREU et al. 2004), que variaram de 0,79 a $1,83 \mathrm{~m}$. Os altos valores para as alturas de plantas podem ser explicados pelo ótimo desenvolvimento da cultura devido às condições de solo, irrigação, e ao manejo da cultura.
Analisando a Tabela 2, dentre as características relacionadas com a produção, uma das mais importantes para a separação das médias foi o NMVP. Para esta variável, o teste $\mathrm{F}$ da análise de variância detectou diferenças significativas entre as linhagens avaliadas no experimento, e o teste de Skott-knott formou três grupos, confirmando as diferenças, apresentando variabilidade de 31 a 79,6 vagens por planta, respectivamente, para as linhagens UENF 15-22-4 e UENF 14-22-3.

Abreu et al. (2004) estudando a diversidade genética entre acessos de feijão-de-vagem de hábito de crescimento indeterminado utilizando análise multivariada, constataram que dentre as características avaliadas, o número médio de vagens por parcela foi a de maior contribuição relativa para o agrupamento dos acessos, sendo esta uma característica de grande importância nos estudos da diversidade genética.

Para o peso médio das vagens (PMV), os acessos UENF 14-4-3, UENF 7-7-1, UENF 14-45, UENF 7-201 e UENF 7-10-1 foram os que produziram vagens com maiores valores.

Variando de 3,81 a 3,53 g, respectivamente. Por outro lado, Pinto et al. (2001) estudando o genótipo comercial de feijão-de-vagem Novirex, observaram a característica peso médio das vagens, com valores superiores aos encontrados no presente estudo, obtendo peso máximo de 5,8 a $7,1 \mathrm{~g}$ entre as vagens com comprimento de $15-20 \mathrm{~cm}$.

O comprimento médio de vagens (CMV) teve as maiores médias nos acessos UENF 7-10-1, UENF 7-20-1 e UENF 14-45, com 18,79; 17,78 e 17,66 cm, respectivamente. Os acessos UENF 14-22-3 e UENF 1526-4 apresentaram 10,53 e 9,31 cm, respectivamente, sendo os de menores CMV (TAB. 2). 
Tabela 2 - Valores Médios para cada uma das características morfoagronômicas, avaliados no experimento de competição de linhagens de feijão-de-vagem, em Bom Jesus de Itabapoana, 2008

\begin{tabular}{|c|c|c|c|c|c|c|c|c|}
\hline Acessos & $\begin{array}{l}\text { APV } \\
(\mathrm{cm})\end{array}$ & $\begin{array}{l}\text { ALT } \\
(\mathrm{m})\end{array}$ & NMVP & $\begin{array}{l}\text { PMV } \\
(\mathrm{g})\end{array}$ & $\begin{array}{l}\text { CMV } \\
(\mathrm{cm})\end{array}$ & NMGV & $\begin{array}{l}\text { Prod.Vagens } \\
\quad\left(\mathrm{kg} \mathrm{ha}^{-1}\right)\end{array}$ & $\begin{array}{l}\text { Prod. Grãos } \\
\qquad\left(\mathrm{kg} \mathrm{ha}^{-1}\right)\end{array}$ \\
\hline UENF 14-45 & $8,70 \mathrm{~B}$ & $2,69 \mathrm{~A}$ & $46,55 \mathrm{~B}$ & $3,75 \mathrm{~A}$ & $17,66 \mathrm{~A}$ & $7,90 \mathrm{~A}$ & $17.243 \mathrm{~A}$ & $2.636,8 \mathrm{~A}$ \\
\hline Feltrin & $8,10 \mathrm{~B}$ & $2,70 \mathrm{~A}$ & $61,00 \mathrm{~A}$ & $2,80 \mathrm{C}$ & $13,42 \mathrm{C}$ & $6,85 \mathrm{~B}$ & $17.066 \mathrm{~A}$ & $1.593,0 \mathrm{~B}$ \\
\hline Top Seed & $8,05 \mathrm{~B}$ & $2,74 \mathrm{~A}$ & $54,29 \mathrm{~A}$ & $3,12 \mathrm{~B}$ & $14,64 \mathrm{~B}$ & $6,80 \mathrm{~B}$ & $17.225 \mathrm{~A}$ & $2.013,8 \mathrm{~B}$ \\
\hline UENF 7-3-1 & $10,60 \mathrm{~A}$ & $2,44 \mathrm{~B}$ & $43,55 \mathrm{C}$ & $3,20 \mathrm{~B}$ & $14,73 \mathrm{~B}$ & $8,10 \mathrm{~A}$ & $13.844 \mathrm{~B}$ & $1.512,4 \mathrm{~B}$ \\
\hline UENF 7-4-1 & 7,17 B & $2,40 \mathrm{~B}$ & $46,25 \mathrm{~B}$ & $3,08 \mathrm{~B}$ & $15,07 \mathrm{~B}$ & $6,65 \mathrm{~B}$ & 14.199 B & $1.845,3 \mathrm{~B}$ \\
\hline UENF 7-5-1 & $11,87 \mathrm{~A}$ & $2,46 \mathrm{~B}$ & $62,25 \mathrm{~A}$ & $3,16 \mathrm{~B}$ & $15,30 \mathrm{~B}$ & $7,70 \mathrm{~A}$ & $19.699 \mathrm{~A}$ & $2.341,6 \mathrm{~A}$ \\
\hline UENF 7-6-1 & $13,10 \mathrm{~A}$ & $2,48 \mathrm{~B}$ & $47,05 \mathrm{~B}$ & $2,65 \mathrm{C}$ & $14,22 \mathrm{~B}$ & $7,85 \mathrm{~A}$ & $12.371 \mathrm{~B}$ & $1.803,0 \mathrm{~B}$ \\
\hline UENF 7-7-1 & $9,10 \mathrm{~B}$ & $2,18 \mathrm{C}$ & $36,65 \mathrm{C}$ & $3,78 \mathrm{~A}$ & $16,15 \mathrm{~B}$ & $8,40 \mathrm{~A}$ & $13.739 \mathrm{~B}$ & $1.756,6 \mathrm{~B}$ \\
\hline UENF 7-9-1 & $9,55 \mathrm{~A}$ & $2,66 \mathrm{~A}$ & $57,15 \mathrm{~A}$ & $2,48 \mathrm{C}$ & $12,93 \mathrm{C}$ & $7,05 \mathrm{~B}$ & $14.238 \mathrm{~B}$ & $1.963,9 \mathrm{~B}$ \\
\hline UENF 7-10-1 & $12,35 \mathrm{~A}$ & $2,70 \mathrm{~A}$ & $46,25 \mathrm{~B}$ & $3,53 \mathrm{~A}$ & $18,79 \mathrm{~A}$ & $8,10 \mathrm{~A}$ & $16.403 \mathrm{~A}$ & $2.067,3 \mathrm{~B}$ \\
\hline UENF 7-12-1 & 5,38 B & $2,75 \mathrm{~A}$ & $47,95 \mathrm{~B}$ & $2,65 \mathrm{C}$ & $14,30 \mathrm{~B}$ & $7,25 \mathrm{~B}$ & $12.515 \mathrm{~B}$ & $1.980,0 \mathrm{~B}$ \\
\hline UENF 7-14-1 & $10,70 \mathrm{~A}$ & $2,27 \mathrm{C}$ & $46,75 \mathrm{~B}$ & $2,57 \mathrm{C}$ & $13,87 \mathrm{C}$ & $7,20 \mathrm{~B}$ & $12.052 \mathrm{~B}$ & $1.683,6 \mathrm{~B}$ \\
\hline UENF 7-20-1 & $8,07 \mathrm{~B}$ & $2,79 \mathrm{~A}$ & $54,80 \mathrm{~A}$ & $3,68 \mathrm{~A}$ & $17,78 \mathrm{~A}$ & 7,05 B & 20.052 A & $2.630,8 \mathrm{~A}$ \\
\hline UENF 7-28-1 & $6,90 \mathrm{~B}$ & $2,44 \mathrm{~B}$ & $42,60 \mathrm{C}$ & $3,11 \mathrm{~B}$ & $15,31 \mathrm{~B}$ & $7,45 \mathrm{~A}$ & $13.040 \mathrm{~B}$ & $1.419,3 \mathrm{~B}$ \\
\hline UENF 9-1-2 & $5,48 \mathrm{~B}$ & $2,32 \mathrm{~B}$ & $52,25 \mathrm{~A}$ & $2,64 \mathrm{C}$ & $13,00 \mathrm{C}$ & $8,00 \mathrm{~A}$ & $13.823 \mathrm{~B}$ & $1.883,4 \mathrm{~B}$ \\
\hline UENF 9-3-2 & $6,80 \mathrm{~B}$ & $2,14 \mathrm{C}$ & $52,85 \mathrm{~A}$ & $2,42 \mathrm{C}$ & $11,71 \mathrm{D}$ & $7,30 \mathrm{~B}$ & $12.814 \mathrm{~B}$ & $1.814,5 \mathrm{~B}$ \\
\hline UENF 9-1-2 & $7,08 \mathrm{~B}$ & $1,47 \mathrm{D}$ & $53,92 \mathrm{~A}$ & $2,74 \mathrm{C}$ & $11,83 \mathrm{D}$ & $7,20 \mathrm{~B}$ & $14.879 \mathrm{~B}$ & $1.647,3 \mathrm{~B}$ \\
\hline UENF 9-24-2 & $8,17 \mathrm{~B}$ & $2,19 \mathrm{C}$ & $51,48 \mathrm{~A}$ & $2,57 \mathrm{C}$ & $13,54 \mathrm{C}$ & $7,45 \mathrm{~A}$ & $13.244 \mathrm{~B}$ & $1.598,1 \mathrm{~B}$ \\
\hline UENF 9-27-2 & $7,85 \mathrm{~B}$ & 2,39 B & $53,40 \mathrm{~A}$ & $2,52 \mathrm{C}$ & $11,93 \mathrm{D}$ & 7,30 B & $13.469 \mathrm{~B}$ & $1.750,6 \mathrm{~B}$ \\
\hline UENF 14-3-3 & 7,63 B & $2,51 \mathrm{~B}$ & $42,20 \mathrm{C}$ & $2,84 \mathrm{C}$ & $13,80 \mathrm{C}$ & $8,30 \mathrm{~A}$ & $12.173 \mathrm{~B}$ & $1.486,9 \mathrm{~B}$ \\
\hline UENF 14-4-3 & $8,70 \mathrm{~B}$ & $2,48 \mathrm{~B}$ & $48,1 \mathrm{~B}$ & 3,81 A & $12,26 \mathrm{D}$ & $7,45 \mathrm{~A}$ & $14.220 \mathrm{~B}$ & $1.526,7 \mathrm{~B}$ \\
\hline UENF 14-6-3 & $9,12 \mathrm{~B}$ & $2,12 \mathrm{C}$ & $50,90 \mathrm{~A}$ & $2,83 \mathrm{C}$ & $11,84 \mathrm{D}$ & $6,95 \mathrm{~B}$ & $16.102 \mathrm{~A}$ & $2.333,3 \mathrm{~A}$ \\
\hline UENF 14-11-3 & $8,40 \mathrm{~B}$ & $2,51 \mathrm{~B}$ & $53,20 \mathrm{~A}$ & $2,53 \mathrm{C}$ & $13,78 \mathrm{C}$ & $7,35 \mathrm{~B}$ & $11.900 \mathrm{~B}$ & $1.635,6 \mathrm{~B}$ \\
\hline UENF 14-16-3 & 7,35 B & $2,38 \mathrm{~B}$ & $58,45 \mathrm{~A}$ & $3,03 \mathrm{~B}$ & $15,32 \mathrm{~B}$ & $7,65 \mathrm{~A}$ & $16.782 \mathrm{~A}$ & $2.014,0 \mathrm{~A}$ \\
\hline UENF 14-22-3 & $8,00 \mathrm{~B}$ & $2,69 \mathrm{~A}$ & $79,60 \mathrm{~A}$ & $2,41 \mathrm{C}$ & $9,31 \mathbf{E}$ & $5,05 \mathrm{C}$ & $19.135 \mathrm{~A}$ & $2.222,3 \mathrm{~A}$ \\
\hline UENF 14-23-3 & 8,17 B & $2,76 \mathrm{~A}$ & $53,70 \mathrm{~A}$ & $2,66 \mathrm{C}$ & $11,88 \mathrm{D}$ & $7,15 \mathrm{~B}$ & $14.257 \mathrm{~B}$ & $1.832,0 \mathrm{~B}$ \\
\hline UENF 15-6-4 & $10,45 \mathrm{~A}$ & $2,60 \mathrm{~A}$ & $47,70 \mathrm{~B}$ & $3,04 \mathrm{~B}$ & $14,54 \mathrm{~B}$ & $7,60 \mathrm{~A}$ & $14.491 \mathrm{~B}$ & $2.027,9 \mathrm{~B}$ \\
\hline UENF 15-7-4 & $9,90 \mathrm{~A}$ & $2,58 \mathrm{~A}$ & $48,05 \mathrm{~B}$ & $2,96 \mathrm{C}$ & $14,56 \mathrm{~B}$ & $7,85 \mathrm{~A}$ & $14.132 \mathrm{~B}$ & $1.854,7 \mathrm{~B}$ \\
\hline UENF 15-8-4 & $9,50 \mathrm{~A}$ & $2,04 \mathrm{C}$ & $77,05 \mathrm{~A}$ & $2,27 \mathrm{C}$ & $11,59 \mathrm{D}$ & $6,55 \mathrm{~B}$ & $17.416 \mathrm{~A}$ & $2.533,7 \mathrm{~A}$ \\
\hline UENF 15-22-4 & $7,25 \mathrm{~B}$ & $2,06 \mathrm{C}$ & $31,00 \mathrm{C}$ & $3,14 \mathrm{~B}$ & $13,42 \mathrm{C}$ & $6,55 \mathrm{~B}$ & 9.742 B & 910,6 B \\
\hline UENF 15-23-4 & $10,90 \mathrm{~A}$ & $2,16 \mathrm{C}$ & $50,85 \mathrm{~A}$ & $3,17 \mathrm{~B}$ & $15,15 \mathrm{~B}$ & 8,90 A & $15.873 \mathrm{~A}$ & $2.693,0 \mathrm{~A}$ \\
\hline UENF 15-25-4 & $10,25 \mathrm{~A}$ & $1,92 \mathrm{C}$ & $47,85 \mathrm{~B}$ & $2,86 \mathrm{C}$ & $13,32 \mathrm{C}$ & $6,35 \mathrm{~B}$ & $13.522 \mathrm{~B}$ & $1.860,5 \mathrm{~B}$ \\
\hline UENF 15-26-4 & $6,80 \mathrm{~B}$ & $2,59 \mathrm{~A}$ & $47,65 \mathrm{~B}$ & $2,52 \mathrm{C}$ & $10,53 \mathrm{E}$ & $6,50 \mathrm{~B}$ & $12.017 \mathrm{~B}$ & $1.700,8 \mathrm{~B}$ \\
\hline
\end{tabular}

Médias seguidas de pelo menos uma mesma letra, na coluna, pertencem a um mesmo grupo, pelo critério de agrupamento de Scott-Knott, a $5 \%$ de significância

O número médio de grão por vagem (NMGV) formou três classes, sendo os acessos UENF 15-23-4, UENF 7-7-1, UENF 14-3-3, UENF 7-10-1, UENF 7-3-1, UENF 91-2, UENF 14-45, UENF 15-7-4, UENF 7-6-1, UENF 7-5-1,
UENF 14-16-3, UENF 15-6-4, UENF 14-4-3, UENF 9-24-2 e UENF 7-28-1 pertencentes à classe com maior NMGV; o acesso UENF 14-22-3 foi a que apresentou menor NMGV $(5,05)$, formando isoladamente uma classe (TAB. 2). 
Avaliando a produtividade de vagens (ProdVagens), os acessos mais produtivos foram UENF 7-20, UENF 7-51, UENF 14-22-3, UENF 15-8-4, UENF 14-45, Top Seed, Feltrin, UENF 14-16-3, UENF 7-10-1, UENF 14-6-3 e UENF 15-23-4, produzindo de 15.873 a $20.052 \mathrm{~kg} \mathrm{ha}^{-1}$ de vagens. Nota-se que dentre este grupo de 11 genótipos mais produtivos, incluindo-se as três testemunhas, existem oito acessos promissores que são tão produtivos quanto o material comercial disponível no mercado e que poderão ser disponibilizados para os produtores como alternativa, uma vez que existem poucos materiais genotípicos disponíveis no mercado e com preço elevado (TAB. 2).

Produtividades médias acima de $20 \mathrm{Mg} \mathrm{ha}^{-1}$ de vagens são consideradas altas para cultivares de feijão-devagem de hábito indeterminado (OLIVEIRA et al., 2003), portanto, estes mesmos autores atingiram produtividades máximas de até $29 \mathrm{Mg} \mathrm{ha}^{-1}$ para esta cultura, no Estado da Paraíba. Peixoto et al. (2002) estudando a adaptabilidade e estabilidade de 15 genótipos de feijão-de-vagem de crescimento indeterminado, em oito ambientes, obtiveram produtividades de $8,09 \mathrm{Mg} \mathrm{ha}^{-1}$ (menor produtividade) até genótipos com 35,7 $\mathrm{Mg} \mathrm{ha}^{-1}$ de vagens (maior produtividade). Estes resultados demonstram o potencial produtivo do feijão-de-vagem.

De acordo com Silva et al. (2004) o mercado de feijão comum no Brasil pode estar sendo afetado pela mudança de hábitos alimentares da população. Caso a produção de feijão não corresponda ao incremento da produção de alimentos, para atender o crescimento populacional, a qualidade da alimentação dos brasileiros, dependentes da proteína de origem vegetal, será gravemente afetada. Para tanto, há necessidade de investimentos em programas de melhoramento, como este da Universidade Estadual do Norte Fluminense, que possam contribuir com a geração de genótipos superiores, de maior produção, maximizando os retornos econômicos aos agricultores.

A produtividade do feijão-de-vagem foi avaliada considerando-se uma segunda alternativa para a comercialização da cultura, a produção de grãos. Apesar de esta cultura destinar-se à produção de vagens frescas para o mercado consumidor, outra possibilidade seria deixar a cultura no campo até a produção de grãos. Esta situação poderia ocorrer se o preço pago pelas vagens estivesse muito baixo no mercado, no momento da colheita, ou se o produtor tivesse escassez de mão-de-obra para colheita das vagens. Esta alternativa seria importante, pois seus grãos são de boa qualidade para o consumo e seria possível obter preços mais altos no mercado do que com o feijão comum. E assim o consumo do feijão comum poderia ser substituído pelo consumo de grãos do feijão-de-vagem.

Para a produtividade de grãos (ProdGrãos), os acessos UENF 15-23-4, UENF 14-45, UENF 7-20-1,
UENF 15-8-4, UENF 7-5-1, UENF 14-6-3, UENF 1422-3 e UENF 14-16-3 formaram a classe mais produtiva. Está incluído neste grupo o genótipo UENF 14-45 que é um dos progenitores que deu origem aos acessos no programa de melhoramento. Assim, observa-se que este grupo é constituído por sete acessos que foram mais produtivos do que as variedades comerciais (Feltrin e Top Seed), as quais, junto com os demais acessos pertenceram ao grupo menos produtivo (TAB. 2). Por outro lado, Bertoldo et al. (2009), trabalhando com rendimento de grãos $\left(\mathrm{kg} \mathrm{ha}^{-1}\right)$ em feijão do grupo comercial carioca e preto, não encontraram diferenças significativas entre os quatro genótipos estudados.

$\mathrm{Na}$ ANOVA Conjunta para o teor de fibra das vagens, não se detectou interação genótipo e ambiente, ou seja, os acessos não sofreram influência do ambiente para o teor de fibras (TAB. 3), mostrando ser uma característica bastante estável. Isto significa que se pode optar pelos resultados da análise de variância conjunta, ou seja, discutir os experimentos conjuntamente. Estes resultados estão de acordo com os encontrados por Carvalho et al. (1999) e Mariguele et al. (2008).

Tabela 3 - Análise de variância conjunta da interação Genótipo $\mathrm{x}$ Ambiente para o teor de fibras nas vagens em (\%), nos ensaios de competição de linhagens de feijão-de-vagem, 2008

\begin{tabular}{lcc}
\hline Fontes de Variação & $\begin{array}{c}\text { Graus de } \\
\text { liberdade }\end{array}$ & $\begin{array}{c}\text { Quadrado } \\
\text { Médio }\end{array}$ \\
\hline Blocos/Local & 2 & $0,0149^{\text {ns }}$ \\
Linhagens (genótipos) & 32 & $0,4049^{*}$ \\
Local & 1 & $0,2017^{\text {ns }}$ \\
Local x Linhagens & 32 & $0,2623^{\text {ns }}$ \\
Resíduo & 64 & 0,2112 \\
\hline \multicolumn{1}{c}{ Total } & 131 & \\
\hline
\end{tabular}

*Significativo a 5\% de significância, pelo teste F; ns: não significativo; Média geral $=0,7348 ; \mathrm{CV}(\%)=51,64$

Analisando conjuntamente os dados, verificase que houve efeito significativo de genótipo, existe diferença significativa detectada pelo teste $\mathrm{F}$, para o teor de fibras nas vagens entre os acessos avaliados. A interação genótipo x local (ambiente) não foi significativa indicando a estabilidade desta característica. Brandão (2001) afirma ser o teor de fibra na vagem afetado muito mais pelo ponto de colheita (época de colheita das vagens) do que entre as épocas de cultivo, sendo que a melhor época de colheita foi aos 25 dias após a antese.

Com base no critério de agrupamento de médias (obtidos de dois locais) de Scott-Knott (TAB. 4), observou- 
se a formação de três grupos, sendo um deles formado por dois acessos (UENF 14-6-3 e UENF 15-23-4) com os maiores teores de fibra 1,84 e $1,47 \%$, respectivamente. $\mathrm{O}$ grupo intermediário reuniu quatro acessos (UENF 14-233, UENF 14-11-3, UENF 14-22-3 e UENF 15-6-4) com os seguintes teores de fibras, respectivamente 1,$14 ; 1,14$; 1,07 e $1,06 \%$. Com isso, pode-se dizer que o teor de fibra nestas linhagens foi mais afetado pelas características de precocidade das mesmas do que pelos ambientes onde foram cultivadas (TAB. 4).

Analisando-se a magnitude destes valores (teores de fibras nas vagens frescas) e considerando a metodologia de extração de fibras onde se emprega a acetona para extração, apesar de o teste de Scott-Knott ter formado três grupos distintos, apenas os acessos UENF 14-6-3 e UENF 15-23-4 pertencem ao primeiro grupo, com valores de fibras mais altos em relação ao material testado, pode ser considerada por possuir alto teor de fibra sendo de pior qualidade para o consumo in natura, pois, de acordo com Peixoto et al. (1993) o teor de fibras estabelecido para a espécie está entre 0,70 a $1,70 \%$. Outros autores também encontraram teores de fibras nesta fabácea dentro destes padrões (ARAÚJO, 2000; OLIVEIRA et al., 2001; OLIVEIRA et al., 2003), conforme estabelecido por Peixoto et al. (1993). Abreu et al. (2004), encontraram teores de fibras nas vagens frescas no feijão-de-vagem abaixo de $0,7 \%$.

Entretanto, na literatura existem resultados cujos teores de fibras nas vagens de feijão-de-vagem são bem mais elevados, dependendo da metodologia de extração empregada e do ponto de colheita das vagens. Oliveira et al. (2001) encontraram teores da ordem de $20 \%$ de fibra bruta em vagens secas de feijão-de-vagem. Mariguele et al. (2008) estudando o controle genético da qualidade da vagem em cruzamento de feijão-de-vagem com feijão comum obtiveram teor médio de fibra nas vagens frescas de 4,78\%. Entretanto, estes autores fizeram as extrações das fibras somente triturando as vagens em liquidificador sem a adição de acetona, somente com água.

A magnitude dos resultados de teores de fibras em feijão-de-vagem encontrada na literatura depende muito da metodologia empregada na extração das fibras. Em metodologia que utiliza somente água e não a acetona no processo de extração das fibras os resultados são muito diferentes, bem como quando se expressa o teor de fibra em relação à matéria fresca ou à matéria seca das vagens. Portanto, deve-se ter o cuidado na comparação dos resultados obtidos com os da literatura, não podendo ser feitas comparações sem

Tabela 4 - Teores médios de fibras nas vagens frescas das linhagens de feijão-de-vagem, avaliadas nos experimentos de competição, em dois locais, em 2008

\begin{tabular}{lclc}
\hline \multicolumn{1}{c}{ Linhagem } & Teor médio de Fibras (\%) & \multicolumn{1}{c}{ Linhagem } & Teor médio de Fibras (\%) \\
\hline UENF 14-6-3 & $1,84 \mathrm{a}$ & UENF 7-28-1 & $0,63 \mathrm{c}$ \\
UENF 15-23-4 & $1,47 \mathrm{a}$ & TOP SEED & $0,63 \mathrm{c}$ \\
UENF 14-23-3 & $1,14 \mathrm{~b}$ & UENF 14-45 & $0,62 \mathrm{c}$ \\
UENF 14-11-3 & $1,14 \mathrm{~b}$ & UENF 7-3-1 & $0,61 \mathrm{c}$ \\
UENF 14-22-3 & $1,07 \mathrm{~b}$ & UENF 9-3-2 & $0,59 \mathrm{c}$ \\
UENF 15-6-4 & $1,06 \mathrm{~b}$ & UENF 9-4-2 & $0,59 \mathrm{c}$ \\
UENF15-26-4 & $0,92 \mathrm{c}$ & UENF 14-3-3 & $0,51 \mathrm{c}$ \\
UENF 15-8-4 & $0,84 \mathrm{c}$ & UENF 7-7-1 & $0,56 \mathrm{c}$ \\
UENF 9-1-2 & $0,77 \mathrm{c}$ & UENF 9-27-2 & $0,52 \mathrm{c}$ \\
UENF 7-10-1 & $0,75 \mathrm{c}$ & UENF 7-6-1 & $0,51 \mathrm{c}$ \\
UENF 9-24-2 & $0,74 \mathrm{c}$ & FELTRIN & $\mathbf{0 , 5 1 ~ c}$ \\
UENF 15-7-4 & $0,74 \mathrm{c}$ & UENF 7-5-1 & $0,49 \mathrm{c}$ \\
UENF 14-16-3 & $0,74 \mathrm{c}$ & UENF 7-14-1 & $0,46 \mathrm{c}$ \\
UENF 14-4-3 & $0,74 \mathrm{c}$ & UENF15-25-4 & $0,43 \mathrm{c}$ \\
UENF 7-12-1 & $0,67 \mathrm{c}$ & UENF 7-4-1 & $0,35 \mathrm{c}$ \\
UENF 7-20-1 & $0,66 \mathrm{c}$ & UENF 15-22-4 & $0,31 \mathrm{c}$ \\
UENF 7-9-1 & $0,65 \mathrm{c}$ & - & - \\
\hline
\end{tabular}

Médias seguidas de mesmas letras pertencem a um mesmo grupo pelo critério de agrupamentos de Scott-Knott, a 10\% de significância 
antes observar os detalhes da metodologia empregada na extração e como os teores de fibras (percentagem relativa) estão sendo expressos ou se os resultados expressam o teor de fibra bruta ou de fibras solúveis.

A fibra bruta tem designação originada de um método analítico, representando apenas uma fração das fibras totais dos alimentos, fração esta que resiste à digestão "in vitro" por ácidos e álcalis. Os valores das fibras brutas não devem expressar a quantidade de fibras de um alimento (OLIVEIRA et al., 2001).

\section{Conclusões}

1. Houve diferença significativa entre os genótipos avaliados;

2. Os acessos UENF 7-20-1, UENF 7-5-1, UENF 14-22-3, UENF 15-8-4, UENF 1445, Top seed blue line, Feltrin, UENF 14-16-3, UENF 7-10-1, UENF 14-6-3 e UENF 15-23-4 foram respectivamente os mais produtivos tanto para peso das vagens frescas quanto para produção de grãos secos;

3. A característica mais correlacionada com os rendimentos de vagens e de grãos foi o NMVP seguido por CMV;

4. O teste de Scott-Knott formou três grupos quanto ao teor de fibra nas vagens frescas. Sendo que os acessos UENF 14-6-3 e UENF 15-23-4 foram os que apresentaram maiores teores de fibras nas vagens.

\section{Referências}

ABREU, F. B. Aplicação de técnicas de análises multivariada em acessos de feijão-de-vagem (Phaseolus vulgaris $L$.) de crescimento indeterminado do banco de germoplasma da UENF. 2001. 69f. (Dissertação de Mestrado em Produção Vegetal). - Universidade Estadual do Norte Fluminense, Campos dos Goytacazes.

ABREU, F. B. et al. Divergência genética entre acessos de feijão-de-vagem (Phaseolus vulgaris L.) de hábito de crescimento indeterminado. Horticultura Brasileira, v. 22, n. 03 , p. 547-552, 2004.

ANUÁRIO ESTATÍSTICO DO ESTADO DO RIO DE JANEIRO. Rio de Janeiro: Centro de Informações e Dado do Rio de Janeiro, 1998. v. 15. cap. 22, p. 322-328.

ARAÚJO, J. S. Produção e qualidade do feijão-de-vagem adubado com esterco suíno e fertilizante mineral. 2000. 74f. (Dissertação de Mestrado em Produção vegetal). -Universidade Federal da Paraíba, Areia.

BERTOLDO, J. G. et al. Correlação entre caracteres de produção e tempo de cocção em feijão em dois ambientes.
Revista Ciência Agronômica, v. 40, n. 01, p. 135-140, 2009.

BRANDÃO, R. A. P. Avaliação da qualidade das vagens e sementes de feijão-vagem (Phaseolus vulgaris L) cvs. UEL-1 e AG-274, em função da idade e da época de cultivo. 2001. 22f. (Dissertação de Mestrado em Agronomia) - Universidade Estadual de Londrina, Londrina.

CARVAlho, A. C. P. P. et al. Capacidade de combinação para oito caracteres agronômicos em cultivares rasteiras de feijão-de-vagem. Horticultura Brasileira, v. 17, n. 02, p. 102-105, 1999.

CEASA - RJ 2006. CENTRAL DE ABASTECIMENTO DO ESTADO DO RIO DE JANEIRO S/A (CEASA). Oferta de produtos Hortícolas. 2006. Disponível em: <http//www. ceasa.rj.gov.br/ consultas/2006/consultas.html>. Acesso: 15 mar. 2008.

CRUZ, C. D. Programa Genes: aplicativo computacional em genética e estatística. Viçosa: UFV, 1997. 442 p.

FRANK, T.; ANHDER, G. I.; CARTER, W. B. Testing snap beans for fiber content. Keystone Seeds, St. Louis, 1961. 8 p.

KUREK, A. J. et al. Análise de trilha como critério de seleção indireta para rendimento de grãos em feijão Revista Brasileira de Agrociência, v. 07, n. 01, p. 29-32, 2001.

LONDERO, P. M. G. et al. Herdabilidade dos teores de fibra alimentar e rendimento de grãos em populações de feijoeiro. Pesquisa agropecuária brasileira, v. 41, n. 01, p. 51-58, 2006.

LONDERO, P. M. G.; RIBEIRO, N. D.; CARGNELUTTI, A. Teores de fibra e rendimento de grãos em populações de feijão. Ciências agrotécnicas, v. 32, n. 01, p. 167-173, 2008.

MACHADO, C. et al. Identificação de genótipos de feijão-caupi quanto à precocidade, arquitetura da planta $\mathrm{e}$ produtividade de grãos. Revista Ciência Agronômica, v. 39, n. 01, p. 114-123, 2008.

MARIGUELE, K. H. et al. Controle genético da qualidade da vagem em cruzamento de feijão-vagem e feijão comum. Pesquisa Agropecuária Brasileira, v. 43, n. 01, p. 47-52, 2008.

OLIVEIRA, F. J.; BASTOS, G. Q.; CARNEIRO, F. W. O. Teor de fibra em genótipos de feijão-vagem. Revista Ecossistema, v. 26, n. 01, p. 65-67, 2001.

OLIVEIRA, A. P de.; SOBRINHO, J. T., SOUZA, A. P. de. Característica e rendimento do feijão-vagem em função de doses e formas de aplicação de nitrogênio. Ciência e Agrotecnologia, v. 37, n. 03 , p. 714-720, 2003.

PEIXOTO, N. et al. Produção de sementes de linhagens e cultivares arbustivas de feijão-de-vagem em Anápolis - GO. Horticultura Brasileira, v. 11, n. 02, p. 151-152, 1993.

PEIXOTO, N. et al. Adaptabilidade e estabilidade em feijão de vagem de crescimento indeterminado. Horticultura Brasileira, v. 20, n. 04 , p. $616-618,2002$. 
PINTO, C. M. F. et al. Idade de colheita do feijão-vagem anão cultivar Novirex. Horticultura Brasileira, v. 19, n. 01, p. 163-167, 2001.

QUEIROGA, J. L. et al. Estimativa da área foliar do feijão-vagem (Phaseolus vulgaris L.) por meio da largura máxima do folíolo central. Horticultura Brasileira, v. 21, n. 01, p. 64-68, 2003.
SILVA, M. P. et al. Análise dialélica da capacidade combinatória em feijão-de-vagem. Horticultura Brasileira, v. 22, n. 02, p. 277-280, 2004.

VALE, N. M. et al. Métodos de semeadura empregados como critério de avaliação fenotípica em melhoramento de feijão. Revista Biotemas, v. 22, n. 04, p. 73-81, 2009. 